\title{
THEORETICAL AND EXPERIMENTAL ANALYSIS OF FORMABILITY OF EXPLOSIVE WELDED Mg/AI BIMETALLIC BARS
}

\begin{abstract}
The paper has presented the results of theoretical studies and experimental tests of the plastic deformation of $\mathrm{Mg} / \mathrm{Al}$ bimetallic specimens. Theoretical studies were carried out using the Forge2011® computer program. Physical modeling, on the other hand, was performed using the Gleeble 3800 simulator. Bimetallic bars of an outer diameter of $22.5 \mathrm{~mm}$ and a cladding layer thickness of $1.7 \mathrm{~mm}$ were obtained by the explosive welding method. Samples for formability tests, characterized by a diameter-to-length ratio of 1 , were taken from the bars. The theoretical studies and experimental tests were carried out for the temperature range from 300 to $400^{\circ} \mathrm{C}$ and for different strain rates. Based on the obtained investigation results it has been found that the main parameters influencing the formability of $\mathrm{Mg} / \mathrm{Al}$ bimetallic bars are strain rate than the process temperature.

Keywords: $\mathrm{Mg} / \mathrm{Al}$ bimetallic bar, plastic deformation, physical modelling, numerical modelling, FEM
\end{abstract}

\section{Introduction}

Magnesium is characterized by low density and excellent ability to dampen vibrations. However, it exhibits low formability during cold deformation due to the fact that its crystal lattice has a limited number of slip systems at ambient temperature $[1,2]$. Another obstacle to its broader use in technology is also the fact of its relatively poor corrosion resistance and considerable abrasive wear. Thus, a prospective solution is to produce a $\mathrm{Mg}$ / $\mathrm{Al}$ products that will provide increased corrosion resistance compared to magnesium sheets and bars produced by different method. For this purpose, it is necessary to produce $\mathrm{Mg}$ / $\mathrm{Al}$ sheets and bars, in which the outer layer will be aluminium or aluminium alloy, with the individual layers being bonded together. Aluminium and its alloys exhibit better formability compared to $\mathrm{Mg}$ alloys $[3,4]$. Therefore, it can be foreseen that an $\mathrm{Mg} / \mathrm{Al}$ bars or sheets would combine the advantages of the both materials, $\mathrm{Al}$ and $\mathrm{Mg}$.

The explosive welding method is categorized into explosive metal working technologies. It consists in surface joining of elements, such as plates [5-6], tubes [7] or bars [8-9] made of different metals [5-13]. Its growing popularity this method owes to the fact that it is uncomplicated and relative cheap, while modern variants of explosives are characterized by high safety during their manufacture and use. The argument that the explosive contains the sufficient energy capability to realize a given metal working method is also important [14].

The properly selected explosive welding parameters ensure a firm bond between the bimetal-forming layers to be obtained. In addition, the explosive welding method enables round bimetallic semi-finished products to be obtained, which are characterized by a circular cross-section symmetry and very good joint quality. The explosive welding method is one o the few methods enabling $\mathrm{Mg} / \mathrm{Al}$ stock to be produced, which is characterized by high bond strength of the bond region $[8,15]$.

The determination of the parameters of the metal forming of bimetallic materials requires a multi-stage investigation process to be carried out, which comprises, among other things, the determination of the temperature, velocity or the value of preset deformation. In the case of joining two metals differing in formability, the method of selecting deformation parameters plays an important role. However, the available literature lacks information on the formability of $\mathrm{Mg} / \mathrm{Al}$ bimetallic bars. One of the first studies, in which the plastic deformation of $\mathrm{Mg} / \mathrm{Al}$ bars (in die forging) was determined, was [16]. Mg/Al bimetallic specimens obtained in the hot hydrostatic extrusion process were used as the stock. A hard and little ductile layer of $\mathrm{Mg} / \mathrm{Al}$ intermetallic phases was formed at the $\mathrm{Mg} / \mathrm{Al}$ bond interface. $\mathrm{The} \mathrm{Mg} / \mathrm{Al}$ specimens were deformed using different forging methods, namely: upsetting, spreading and rising. Although the test results showed a possibility of presetting large deformations, in some instances, however, intermetallic phase cracks occurred at the bond interface [16]. The authors' earlier work [17] reports the results of tests for the plasticity of round AZ31 alloy specimens and for the effect of the aluminium cladding layer (in $\mathrm{Mg} / \mathrm{Al}$ bimetallic specimens) on extending their formability range. The conducted experimental tests have shown that the application of the clad layer considerably extends the range

\footnotetext{
* CZESTOCHOWA UNIVERSITY OF TECHNOLOGY, FACULTY OF PRODUCTION ENGINEERING AND MATERIALS TECHNOLOGY, INSTITUTE OF METAL FORMING AND SAFETY ENGINEERING, 19 ARMII KRAJOWEJ AV., 42-200, CZESTOCHOWA, POLAND

\# Corresponding author: mroz@wip.pcz.pl
} 
of process parameters (such as temperature and strain rate), with which the AZ31 alloy can be deformed.

Thus, the aim of the study is to determine the effect of process parameters on the formability of $\mathrm{Mg} / \mathrm{Al}$ bimetallic bars, bond quality and the changes occurring in the structure.

The formability of $\mathrm{Mg} / \mathrm{Al}$ bimetallic specimens was determined from compression tests using the Gleeble3800 system. The Forge2011 ${ }^{\circledR}$ computer program was employed to the theoretical analysis of $\mathrm{Mg} / \mathrm{Al}$ bimetallic specimens formability. As the obtained semi-finished product in the form of round $\mathrm{Mg} / \mathrm{Al}$ explosively welded bars would be used as stock for rolling in groove rolling, the adopted range of both physical and numerical studies corresponded to the conditions of groove rolling on the laboratory D150 two-high mill.
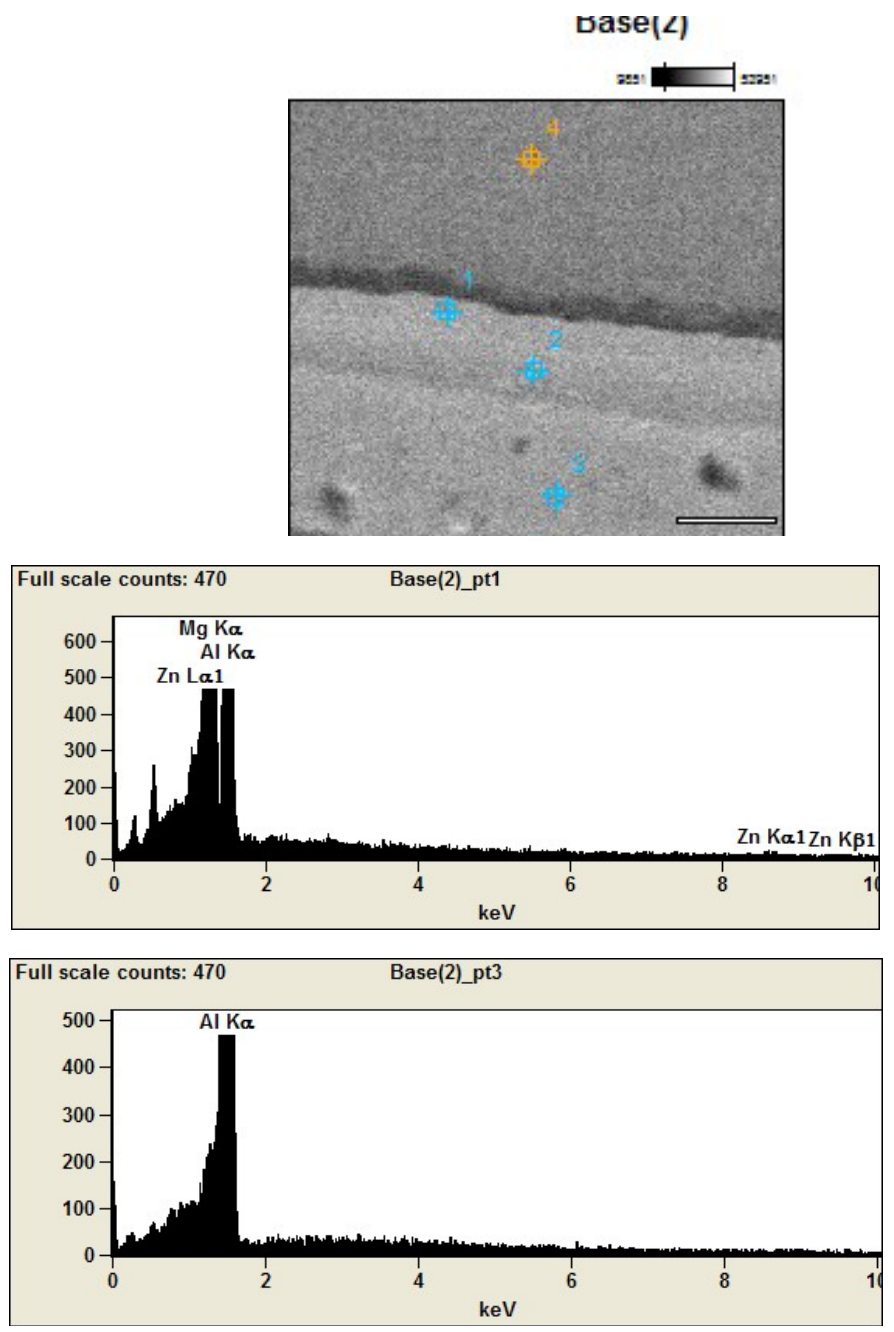

Fig. 1. The results of the punctual EDS analysis of the $\mathrm{Mg} / \mathrm{Al}$ bond region

The quality of the joint of bimetal layers with the magnesium cores clad with aluminium was tested on testing dies [15]. The mechanical tests of the joint were performed on a Zwick Z100 testing machine. The shearing stress values of av. 60 $\mathrm{MPa}$ correspond, from the plasticity condition, to the UTS for aluminium (approx. $100 \mathrm{MPa}$ ).

\section{Materials and testing methodology}

Bimetallic bars with an outer diameter of $22.5 \mathrm{~mm}$ and a aluminium layer thickness of $1.7 \mathrm{~mm}$ were manufactured using an explosive welding method. The explosive welding of bimetallic stocks was made in cooperation with the company Explomet (Poland). The initial dimensions of tubes and bars and the technological parameters used for explosive welding are summarized in papers $[8,17]$. The stock materials were round AZ31 magnesium alloy bars covered with an AW-1050A aluminium layer. The metallographic examination showed that the bond quality in the specimens was very good. No discontinuities or delaminations in the bond region were found. The bonding between individual bimetal components is with a few micrometers thickness transition layer at the bond boundary (Fig. 1).

\author{
Image Name: Base(2); \\ Accelerating Voltage: $20.0 \mathrm{kV}$
}

Magnification: 5000
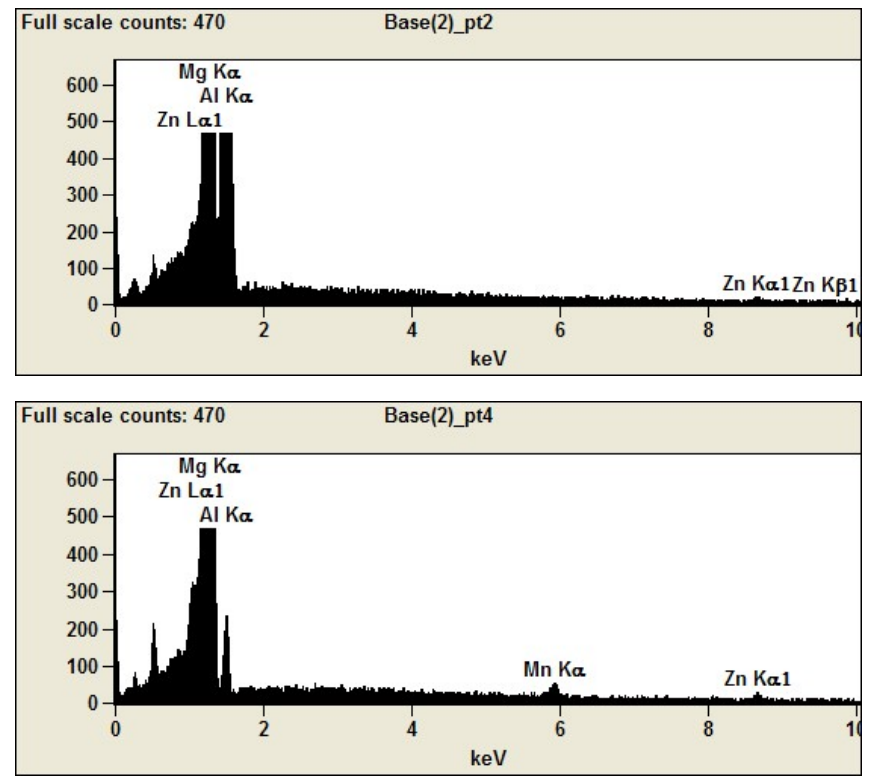

The flow stress $\left(\sigma_{f}\right)$ as dependent on the metal forming process parameters was determined by hot compression tests. The deformation parameters in $\mathrm{Mg} / \mathrm{Al}$ specimens compression tests were selected so that they corresponded the groove-rolling process in laboratory conditions. The following parameters were adopted for the plastometric tests: relative deformation, $50 \%$; 
strain rate, $0.1,1,10 \mathrm{~s}^{-1}$ and temperature, $300^{\circ} \mathrm{C}, 350^{\circ} \mathrm{C}$ and $400^{\circ} \mathrm{C}$. The authors' previous study [17] has discussed the effect of the above-mentioned range of parameters on the behaviour of the plastic flow curves and the possibility of cracks appearing in the deformed round $\mathrm{Mg}$ alloy and $\mathrm{Mg} / \mathrm{Al}$ bimetallic specimens. The study referred to above has shown that with the decrease in deformation temperature to $300^{\circ} \mathrm{C}$ and the increase in strain rate value at that temperature to $1 \mathrm{~s}^{-1}$, cracks might occur in the magnesium core. The use of the smallest strain rate of $0.1 \mathrm{~s}^{-1}$ goes beyond the range corresponding to the bar groove rolling conditions. Therefore, in this study, the testing range was narrowed down to strain rates of 1 and $10 \mathrm{~s}^{-1}$ two temperatures, 350 and $400^{\circ} \mathrm{C}$, at which deformed specimens were characterized by the required ductility, owing to which no crack occurred in them, and the testing range itself was consistent with the conditions of rolling in laboratory conditions.

The schedule of the compression test is shown in Fig. 2a. Whereas, the study has limited itself to the analysis of the region situated under the anvil's immediate action, as the most heavily deformed (the region A in Fig. 2b).
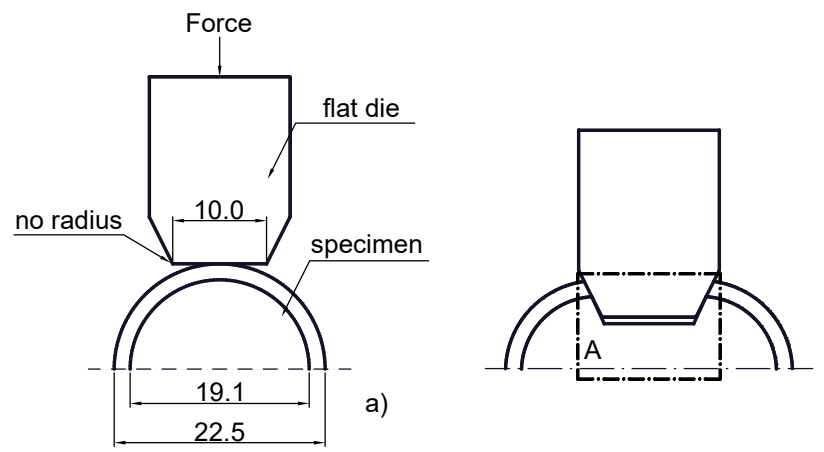

Fig. 2. The schedule of compression test using the Gleeble 3800 simulator $-a$ ) and the view of the analyzed area of the specimen after deformation $-b$ )

The examinations of the structure of the $\mathrm{Mg} / \mathrm{Al}$ specimens after compression tests were carried out using a Nikon Eclipse MA-200 microscope. The assessment of the effect of deformation on the microstructure was made on a Hitachi S-3400N scanning electron microscope (SEM) with a tungsten gun equipped with an attachment for the examination of crystallographic orientations using the Kikuchi line diffraction image.

\section{Initial Parameters Implemented for Numerical Computations}

The thermo-mechanical simulation of the compression tests was carried out with the use of a visco-plastic model in the triaxial state of strain by using the Forge $2011 \AA$ program, whereas the properties of the deformed material were described according to the Norton-Hoff [18-19] conservation law. The application of the computer program Forge2011 ${ }^{\circledR}$ using the thermo-mechanical models that it contains requires the definition of boundary conditions which are decisive to the correctness of numerical computation. The properties of the aluminium and magnesium alloy examined, friction conditions, and the kinetic and thermal parameters describing the physical modeling of the process.

The theoretical analysis was performed for the compression tests conditions: friction coefficient, $\mu-0.15$; specimens temperature -350 and $400^{\circ} \mathrm{C}$. The plastic flow strain, as dependent on the temperature and strain parameters for individual bimetallic specimen components, i.e. aluminium and the magnesium alloy, was determined based on hot compression tests for the plane state of strain in the Gleeble 3800 metallurgical process simulator. For the description of the properties of the investigated materials, the Hensel-Spittel function [20] in the following form was employed:

$$
\sigma_{f}=A_{1} \exp ^{m_{1} T} \varepsilon^{m_{2}} \exp ^{\varepsilon m_{4}} \dot{\varepsilon}^{m_{3}}(1+\varepsilon)^{\frac{m_{5}}{\varepsilon}} \exp ^{\varepsilon m_{7}} \dot{\varepsilon}^{m_{8} T} T^{m_{9}}
$$

where: $\sigma_{f}$ - flow stress $[\mathrm{MPa}], T-$ temperature $\left[{ }^{\circ} \mathrm{C}\right], \varepsilon-$ true strain, $\dot{\varepsilon}-$ strain rate $\left[\mathrm{s}^{-1}\right], A_{1}, m_{1} \div m_{9}$ - coefficients.

Based on the performed approximation of the results of plastometric testing of the materials used for the investigation with function (1), the values of the flow stress function coefficients were obtained, which are given in table 1.

The use of the explosive welding method for making bimetallic stocks ensures a firm bond of the components to be achieved. Thus, in numerical simulations, the bond between the magnesium core and the aluminium cladding layer was defined as firmly adhering. The nodes of both meshes were not connected. In order to increase the speed and accuracy of computations, $1 / 4$ of the bimetallic specimen cross-section were used in the simulations.

TABLE 1

Coefficients of the flow stress function (1)

\begin{tabular}{|c|c|c|c|c|c|c|c|c|c|}
\hline \hline Material & $\boldsymbol{A}_{\mathbf{1}}$ & $\boldsymbol{m}_{\mathbf{1}}$ & $\boldsymbol{m}_{\mathbf{2}}$ & $\boldsymbol{m}_{\mathbf{3}}$ & $\boldsymbol{m}_{\mathbf{4}}$ & $\boldsymbol{m}_{\mathbf{5}}$ & $\boldsymbol{m}_{\mathbf{7}}$ & $\boldsymbol{m}_{\mathbf{8}}$ & $\boldsymbol{m}_{\mathbf{9}}$ \\
\hline AW-1050A & 0.08743 & -0.0099 & 0.11325 & -0.08845 & -0.00058 & -0.00153 & 0.196267 & 0.00048 & 1.71527 \\
\hline AZ31 & 0.68478 & -0.0072 & 0.34242 & 0.02864 & -0.08199 & -0.00023 & -0.00439 & 0.00022 & 1.41094 \\
\hline
\end{tabular}

\section{Results and discussion}

At the first investigation stage, the $\mathrm{Mg} / \mathrm{Al}$ bimetallic specimen plastic flow curves obtained from physical and numerical modelling were compared (Fig. 3).
By comparing the plastic flow curves for $\mathrm{Mg} / \mathrm{Al}$ bimetallic specimens (Fig. 3), a slight difference in force values obtained from numerical simulation and physical modelling, with the identical parameters (strain rate, deformation, temperature), was found. Whereas, greater differences, both qualitative and 

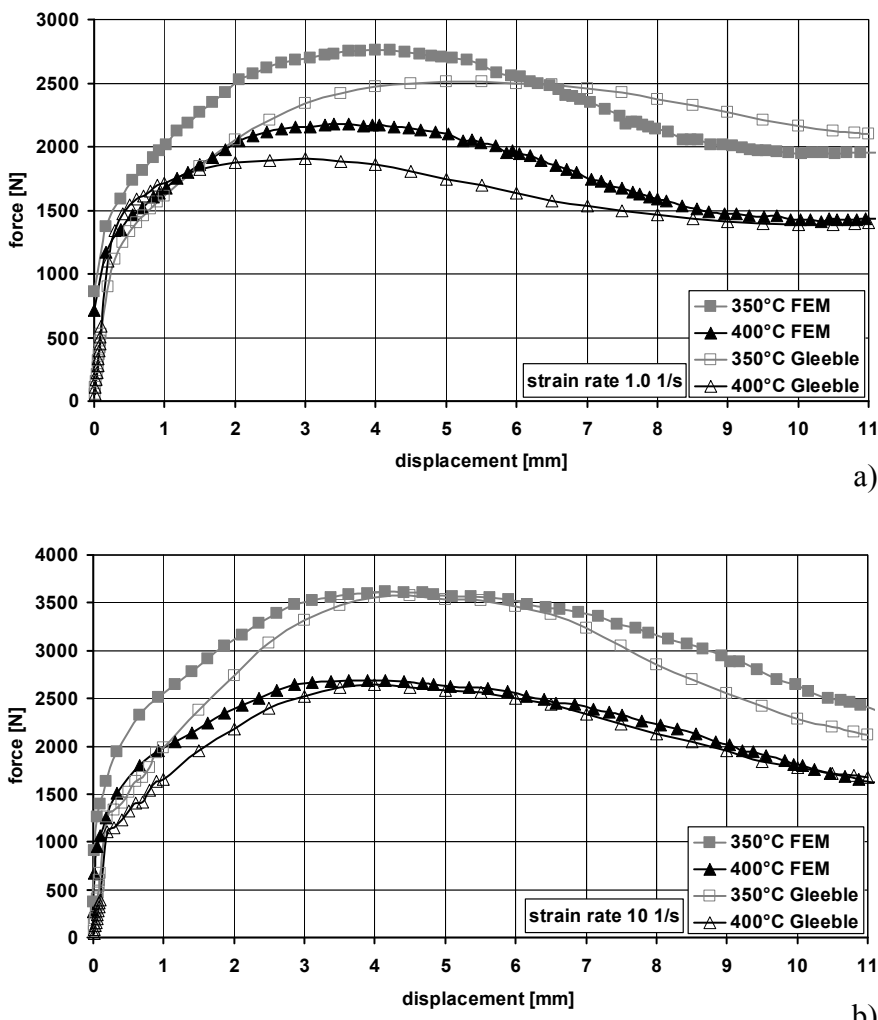

Fig. 3. Force vs. displacement curves obtained from compression tests of $\mathrm{Mg} / \mathrm{Al}$ bimetallic specimens: a) strain rate $1 \mathrm{~s}^{-1}, \mathrm{~b}$ ) strain rate $10 \mathrm{~s}^{-1}$

quantitative, were noted for bimetallic specimens deformed at a strain rate of $1 \mathrm{~s}^{-1}$ (Fig. 3a), compared to the values obtained for specimens deformed at a strain rate of $10 \mathrm{~s}^{-1}$ (Fig. 3b). A greater agreement was obtained the temperature $400^{\circ} \mathrm{C}$. This is the result of the decreasing value of the plastic flow resistance of the Al layer compared to the magnesium core with increasing deformation temperature, whereby the force needed for plastic deformation of the clad layer decreased. Thus, the recorded force variation results chiefly from the deformation of the magnesium core. In both cases, the force values obtained from numerical simulations were slightly greater than those recorded during the compression tests, which might be caused by the slight rotation of the specimens around their axis as the experiment was conducted (Fig. 4), that cold have been caused by an asymmetric positioning of the specimens between the anvils and the small initial surface area of contact between the specimens and the anvils. Using 2 axes of symmetry in the compressive test computer simulations eliminated the problem of uncontrolled specimen rotation.

From the testing results represented in Fig. 3 it can be found that, as expected, there is a great influence of the strain rate and temperature on the value of force variation. Regardless of the strain rate applied, the increase of temperature causes a decrease in the force value. By contrast, the increase of the strain rate results in an increase in the value of force needed for deforming $\mathrm{Mg} / \mathrm{Al}$ specimens.

Fig. 4 shows the shapes of $\mathrm{Mg} / \mathrm{Al}$ bimetallic specimens after compression tests of the Gleeble3800 simulator.
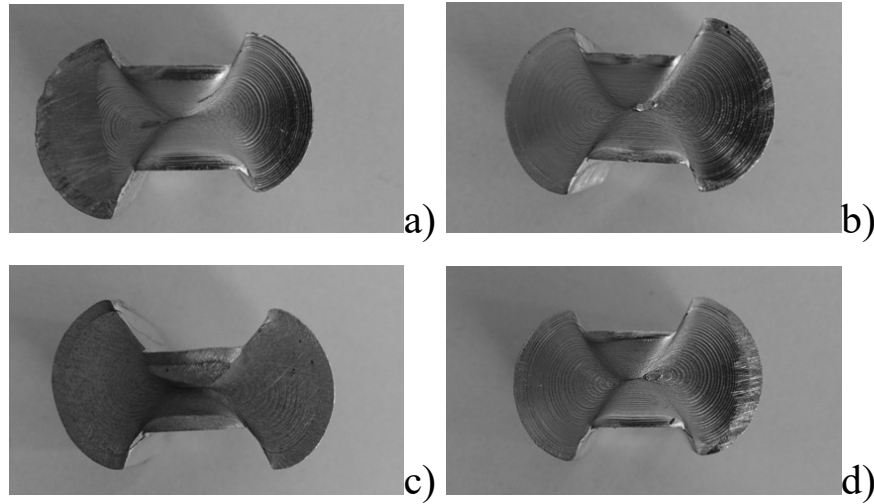

Fig. 4. View of $\mathrm{Mg} / \mathrm{Al}$ specimens after compression tests: a) $350^{\circ} \mathrm{C}$, strain rate $1 \mathrm{~s}^{-1}$, b) $350^{\circ} \mathrm{C}$, strain rate $10 \mathrm{~s}^{-1}$, c) $400^{\circ} \mathrm{C}$, strain rate $1 \mathrm{~s}^{-1}$, d) $400^{\circ} \mathrm{C}$, strain rate $10 \mathrm{~s}^{-1}$

The employed temperature and deformation parameters provided the possibility of deforming the $\mathrm{Mg} / \mathrm{Al}$ bimetallic specimens without losing the integrity of the magnesium core. No cracks whatsoever, nor delaminations at the joint boundary in specimen regions directly affected by the anvils were observed. For the temperature range used, as a result of applying the cladding layer that acts as a "lubricant", the most heavily deformed central parts of $\mathrm{Mg} / \mathrm{Al}$ specimens accumulated deformation without a break in cladding layer continuity.

To explain the effect of the adopted range of process parameters on the formability of $\mathrm{Mg} / \mathrm{Al}$ specimens, numerical modelling of compression tests was performed. Figure 5 shows the $\mathrm{Mg} / \mathrm{Al}$ specimen shapes obtained from compression test numerical computations.
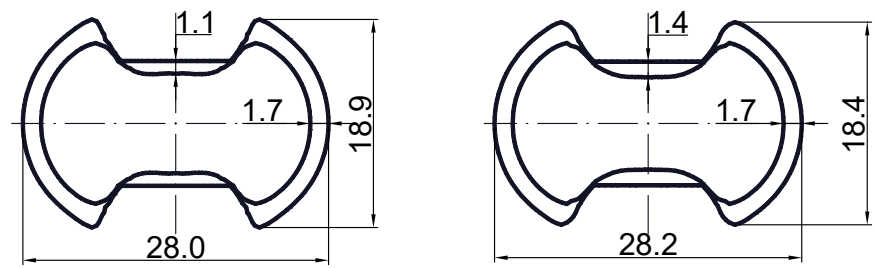

a)

b)
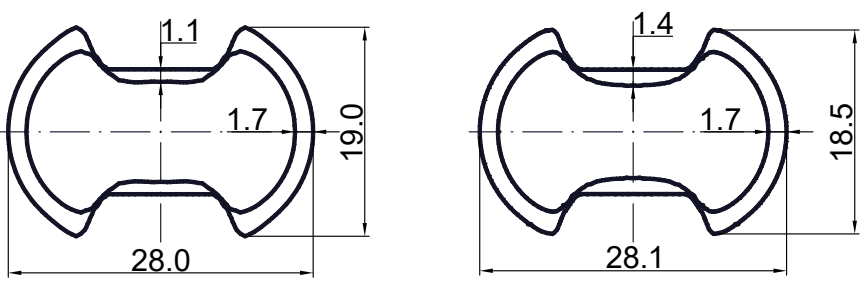

c)

d)

Fig. 5. View of $\mathrm{Mg} / \mathrm{Al}$ cross-section specimens after numerical modeling of compression tests: a) $350^{\circ} \mathrm{C}$, strain rate $1 \mathrm{~s}^{-1}$, b) $350^{\circ} \mathrm{C}$, strain rate $10 \mathrm{~s}^{-1}$, c) $400^{\circ} \mathrm{C}$, strain rate $1 \mathrm{~s}^{-1}$, d) $400^{\circ} \mathrm{C}$, strain rate $10 \mathrm{~s}^{-1}$

By analyzing the data represented in Fig. 5 it can be found that the most deformed locations in the $\mathrm{Mg} / \mathrm{Al}$ specimens are places that are under the direct effect of both the upper and the lower anvil. This applies both to the cladding layer and to the 
magnesium core of the specimens. Figure 5 shows that the process parameter that most significantly influences the deformation of individual $\mathrm{Mg} / \mathrm{Al}$ specimen components is the strain rate, rather than the process temperature itself. Increasing the strain rate from 1 to $10 \mathrm{~s}^{-1}$ has caused in this case a lesser reduction in cladding layer thickness, regardless of the compression test temperature used. The increase of strain rate causes the value of plastic flow stress in the soft cladding layer to grow faster, compared to the cladding layer deformed at a lower strain rate. This causes an increase in its plastic flow resistance, which results in a lesser reduction in its height. The preset deformation penetrates more intensively into the middle regions of the magnesium core. The significant influence of strain rate on the cladding layer formability is evidenced also by the mode of variation of cladding layer thickness in regions situated immediately under the flat anvil part. Applying a lower strain rate value makes the cladding layer uniformly deformed across the entire length of the specimen and anvil contact. The boundary of the joint of individual bimetal layers resembles a straight line. By contrast, the increase in strain rate causes an uneven deformation of the cladding layer, whose distribution on the joint boundary in regions affected by the anvils is similar in shape to an arc. Increasing the strain rate level causes also a change in the mode of $\mathrm{Mg} / \mathrm{Al}$ specimen plastic flow in freely deformed regions. For specimens deformed at a higher strain rate, the material more intensively widened and its height decreased. In the case of a lower strain rate, only the aluminium layer widened, thus its thickness was smaller compared to that obtained at a higher strain rate (Fig. 5). The increase in temperature did not cause any changes in the plastic flow of individual specimens.

A confirmation of the more significant effect of strain rate than that of temperature are also the variations of the force during deformation of $\mathrm{Mg} / \mathrm{Al}$ bimetallic specimens (Fig. 3). The change of the strain rate value increased the force more than the change of the specimen deformation temperature did.

As during the course of the compressive tests the specimens underwent a slight rotation around the longitudinal axis (Fig. 4), the distribution of cladding layer thickness on the upper and the lower specimen surface was different. In view of the above, there is no possibility of comparing individual cladding layer thickness distributions obtained from physical modelling and numerical simulations of compressive testing.

Figure 6 and 7 show the distributions of strain intensity on the cross-section of $\mathrm{Mg} / \mathrm{Al}$ bimetallic specimens.

The data in Figs. 6 and 7 suggests that increasing the strain rate influences the distribution of strain in the examined $\mathrm{Mg} / \mathrm{Al}$ specimens. Applying a smaller strain rate value causes the cladding layer to be more uniformly deformed across the width of the region immediately affected by the flat anvil part, which contributes to a more uniform cladding distribution along the width. In contrast, increasing the strain rate value causes the $\mathrm{Al}$ layer to be deformed less uniformly across the flat anvil partaffected width. The values of deformation in the middle specimen part get equalized with the values of deformation in this zone for the magnesium core (the lesser deformation of those

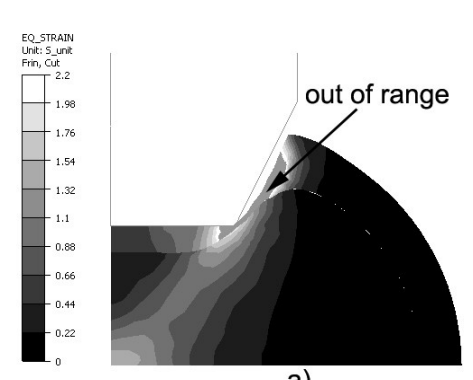

a)

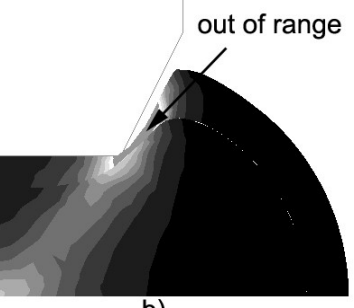

b)
Fig. 6. Distribution of effective strain in the $\mathrm{Mg} / \mathrm{Al}$ specimens after compression tests (temperature of $350^{\circ} \mathrm{C}$ ): a) strain rate $1 \mathrm{~s}^{-1}, \mathrm{~b}$ ) strain rate $10 \mathrm{~s}^{-1},(1 / 4$ of the specimen $)$

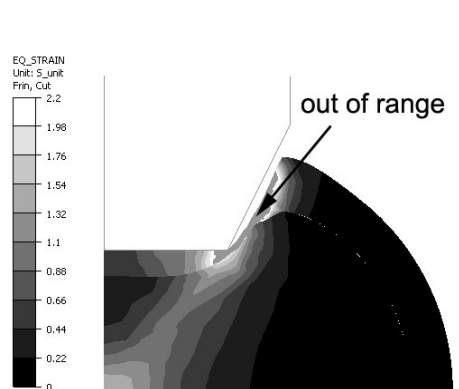

a)

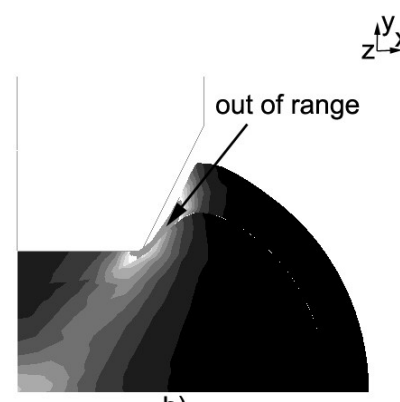

b)
Fig. 7. Distribution of effective strain in the $\mathrm{Mg} / \mathrm{Al}$ specimens after compression tests (temperature of $400^{\circ} \mathrm{C}$ ): a) strain rate $1 \mathrm{~s}^{-1}$, b) strain rate $10 \mathrm{~s}^{-1}$ (1/4 of the specimen)

regions compared to the extreme Al layer regions in contact with the tool), which causes a more uniform distribution of the clad thickness. In both cases, the maximal deformation values cause a so-called "forging cross" to occur in the deformed specimens.

Furthermore, Figs. 6 and 7 show that the highest effective strain levels occur in the Al cladding layer being under the effect of the lateral anvil surfaces (the deformation region beyond the scale range). In extreme cases, as the anvil penetrates into the material being deformed, this may cause the cladding layer continuity to break, as shown in Fig. 8a. For the temperature and strain parameters examined in the study, in spite of its very large deformation, the clad layer did not brake (Figs. $8 \mathrm{~b}$ and 8c). Just as for the shape of the specimens shown in Fig. 5, no significant effect of temperature on the effective strain value was observed. In all cases, the lateral surfaces of specimens are not deformed, which results in the absence of any changes in the thickness of the cladding layer in those $\mathrm{Mg} / \mathrm{Al}$ specimen regions.

The characteristic distribution of effective strain for upsetting tests (the occurrence of a ,forging cross") causes tangential stress to occur in the most deformed regions, resulting in the shearing of the material (Figs. 8 and 9).

As Figures 8 and 9 show, with the increase in strain rate value, tangential stress and its affected region increase, which is especially visible for the magnesium core. The increase in the value of tangential stress due to the increase of strain rate and the decrease of the process temperature causes intensive shear bands to occur in those regions, which significantly contribute to structure refinement. However, in extreme cases, they initiate 
506

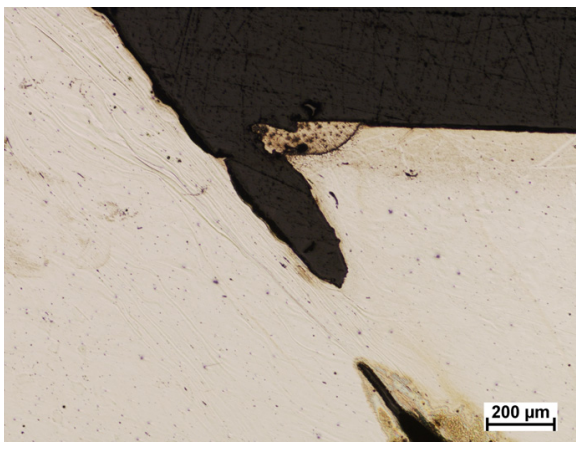

a)

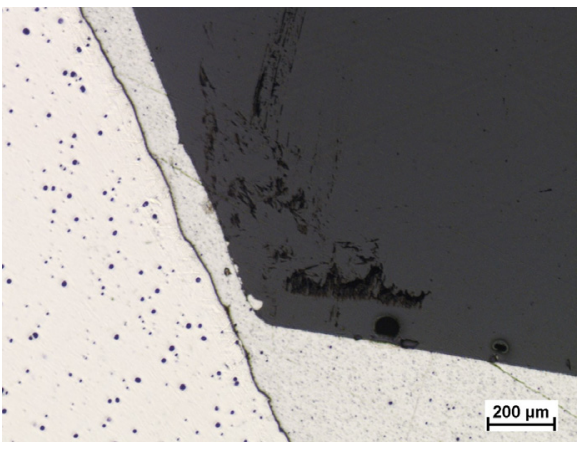

b)

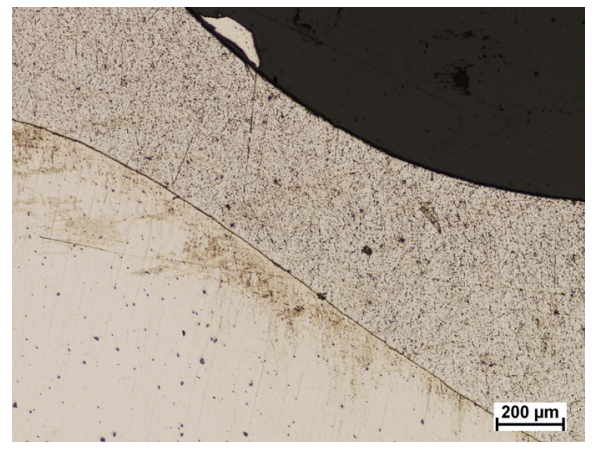

c)

Fig. 8. A view of regions of $\mathrm{Mg} / \mathrm{Al}$ bimetallic specimens deformed at a strain rate of $1 \mathrm{~s}^{-1}$ at a temperature of: a) $\left.300^{\circ} \mathrm{C}, \mathrm{b}\right) 350^{\circ} \mathrm{C}$ and c) $400^{\circ} \mathrm{C}$

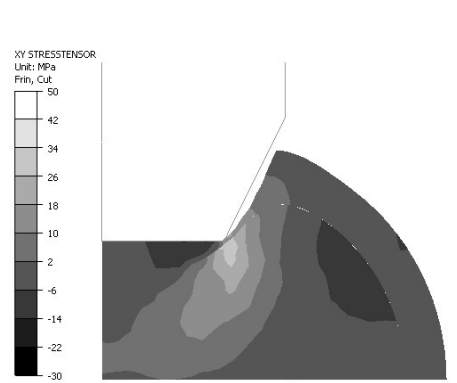

a)

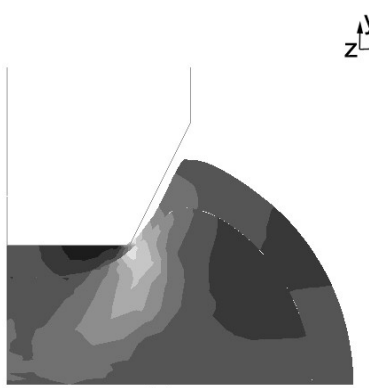

b)

Fig. 9. Distribution of the component $\tau_{x y}$ tangential stress in the $\mathrm{Mg} / \mathrm{Al}$ specimens after compression tests (temperature of $350^{\circ} \mathrm{C}$ ): a) strain rate $\left.1 \mathrm{~s}^{-1}, \mathrm{~b}\right)$ strain rate $10 \mathrm{~s}^{-1}$ (1/4 of the specimen)

microcracks in the material; this causes a delamination of the deformed bimetallic specimens, as has been demonstrated in the authors' previous study [17].

To verify the theoretical study results, an analysis of the joint regions was made using scanning microscopy. For the analysis, regions of compression tested $\mathrm{Mg} / \mathrm{Al}$ specimens were

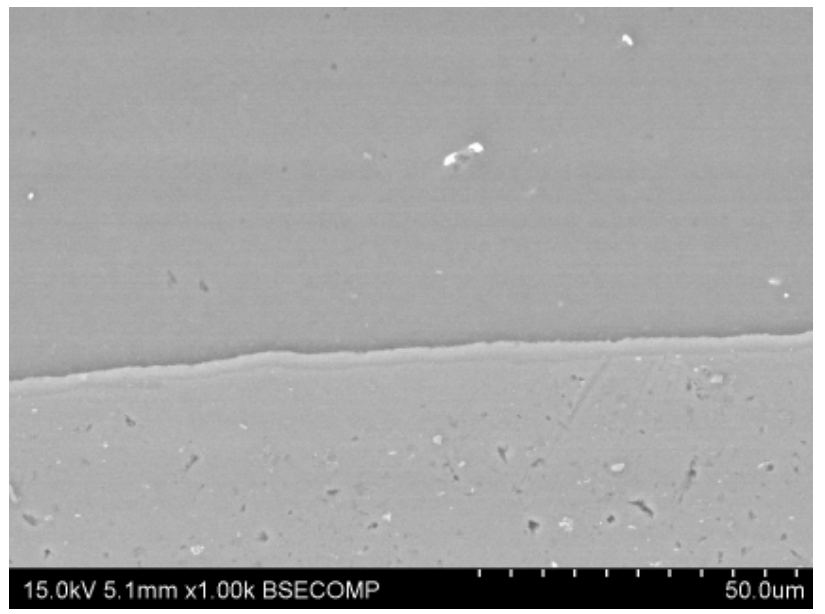

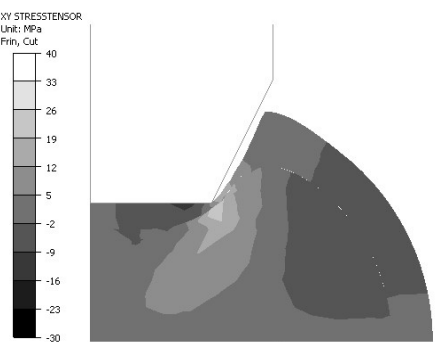

a)

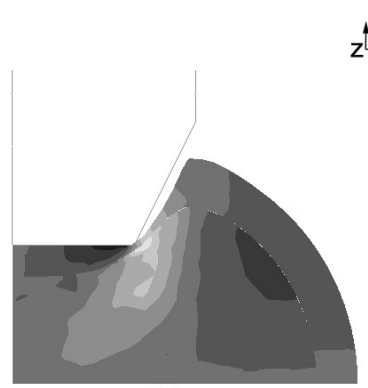

b)
Fig. 10. Distribution of the component $\tau_{x y}$ tangential stress in the $\mathrm{Mg} / \mathrm{Al}$ specimens after compression tests (temperature of $400^{\circ} \mathrm{C}$ ): a) strain rate $\left.1 \mathrm{~s}^{-1}, \mathrm{~b}\right)$ strain rate $10 \mathrm{~s}^{-1}(1 / 4$ of the specimen)

selected, which were immediately affected by the flat anvil part. The data in Fig 11 shows that the applied process parameters provided a very good bond quality throughout the region under analysis. No discontinuities or delaminations were observed at the joint boundary, and the layer of intermetallic phases was continuous and of uniform thickness.

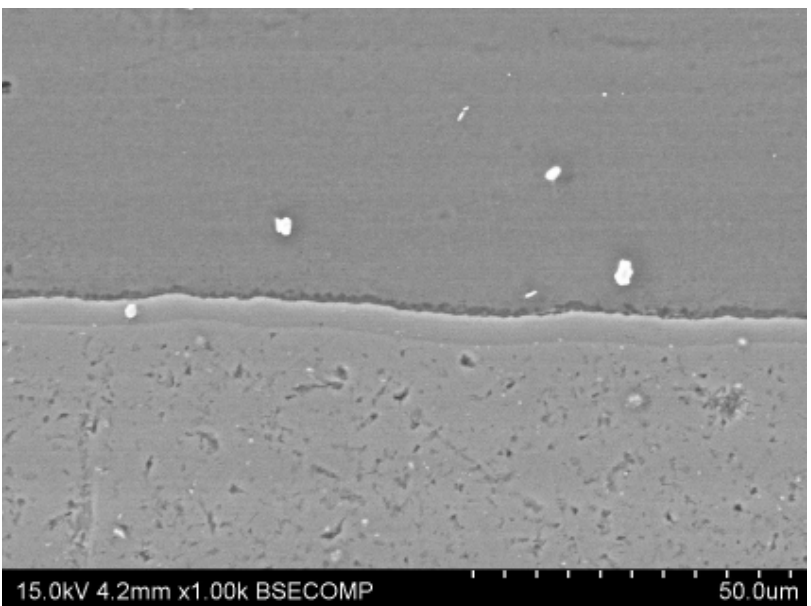

$15.0 \mathrm{kV} 4.2 \mathrm{~mm} \times 1.00 \mathrm{k}$ BSECOMP

Fig. 11. The bond region after the deformation of $\mathrm{Mg} / \mathrm{Al}$ bimetallic specimens at a strain rate of $1 \mathrm{~s}^{-1}$ : a) at a temperature of $350^{\circ} \mathrm{C}$, and $\mathrm{c}$ ) at a temperature of $400^{\circ} \mathrm{C}$ 


\section{Summary}

The conducted experimental tests have shown that the correct selection of temperature and speed conditions enables the determination of the plastic deformation of $\mathrm{Mg} / \mathrm{Al}$ bimetallic specimens without the lost of their integrity. A parameter that influences the plastic flow of individual $\mathrm{Mg} / \mathrm{Al}$ specimen components more than the process temperature does is the strain rate. The obtained investigation results will be helpful in estimating or modelling industrial metal forming processes (groove-rolling process) for $\mathrm{Mg} / \mathrm{Al}$ bimetallic bars.

\section{Acknowledgement}

The study is financed in the years 2015-2018 from the National Scientific Centre's resources granted under Decision no. DEC-2013/11/B/ ST8/04352/1

\section{REFERENCES}

[1] D. Kuc, E. Hadasik, I. Bednarczyk, Solid State Phenomena 191, 101 (2012)

[2] D. Kuc, E. Hadasik, I. Schindler, P. Kawulok, R. Sliwa, Arch. of Met. and Mat. 58 (1), 151 (2013).

[3] S.M Hirth, G.J Marshall, S.A Court, D.J Lloyd, Mat. Sci. and Eng. A 319-321, 452 (2001)

[4] M. Keigler, H. Bauer, D. Harrison, Anjali K.M. De Silva, J. of Mat. Proc. Techn. 167, 363 (2005).
[5] N. Zhang, W. Wang, X. Cao, J. Wu, Materials \& Design 65, 1100 (2015)

[6] I.A. Bataev, A.A. Bataev, V.I. Mali, D.V. Pavliukova, Materials \& Design 35, 225 (2012)

[7] A. Tajyar, A. Masoumi, J. of Mech. Sc. and Techn. 30 (9), 4299 (2016).

[8] S. Mróz, G. Stradomski, H. Dyja, A. Galka, Arch. Civil Mech. Eng. 15 (2), 317 (2015).

[9] A.G. Mamalis, A. Szalay, N.M. Vaxevanidis, D.E. Manolakos, J. of Mat. Proc. Techn. 83 (1), 48 (1998).

[10] M. Asemabadi, M. Sedighi, M. Honarpisheh, Mat.s Sc. and Eng. A 558, 144 (2012).

[11] N. Kahraman, B. Gülenç, F. Findik, J. of Mat. Proc. Techn. 169 (2), 127 (2005)

[12] A. Durgutlu, B. Gülenç, F. Findik, Materials \& Design 26 (6), 497 (2005).

[13] S.A. Mousavi, P. F. Sartangi, Materials \& Design 30 (3), 459 (2009).

[14] T.Z. Blazynski, Explosive Welding, Forming and Compaction, Springer, (1983)

[15] H. Dyja, S. Mroz, Z. Stradomski, Metalurgija 42 (3), 185 (2003).

[16] C. Binotsch, A. Feuerhack, B. Awiszus, M. Handel, D. Nickel, D. Dietrich, Forming of Co-Extruded Al-Mg Hybrid Compounds, Conf. Meform 2014, Altenberg, Saxony, Conference Procedings, 94 (2014).

[17] S. Mróz, P. Szota, T. Bajor, A. Stefanik, Key Engineering Materials 716, 114 (2016).

[18] F.H. Norton, Creep of Steel at High Temperature, New York 1929.

[19] N.J. Hoff, Appl. Mech. 2 (1954).

[20] A. Hensel, T. Spittel, Kraft - und Arbeitsbedarf bildsamer Formgebungsverfahren, Deutscher Verlag für Grundstoffindustrie, Leipzig 1978. 